\title{
A Cross-cultural Assessment of Knowledge, Attitude, and Practice on COVID-19 among People of Afghanistan, Iran, and Turkey
}

\author{
Abbas Ali Husseini ${ }^{1}$, Mohammad Musa Shirzad ${ }^{2}$, Emel Çakar ${ }^{3}$, Mehran Rostamzade $^{4}$, Musa Joya ${ }^{5,6}$, Reza \\ Khaki $^{7}$, Mehrad Khosravi ${ }^{8}$, Freshta Amiry ${ }^{9}$, Nerges Ghadiri ${ }^{10}$, Maryam Hosseini ${ }^{11}$ \\ ${ }^{1}$ Life Science, and Biomedical Engineering Application and Research Center, Istanbul Gelisim University, Istanbul, Turkey \\ ${ }^{2}$ Department of Pharmaceutical Chemistry, Faculty of Pharmacy, Kabul University, Kabul, Afghanistan \\ ${ }^{3}$ Health Services Vocational School, Istanbul Gelisim University, Istanbul, Turkey. \\ ${ }^{4}$ Psychology Department; Faculty of Economics; Administrative and Social Sciences; Istanbul Gelisim University, Istanbul, \\ Turkey \\ ${ }^{5}$ Department of Medical Physics and Biomedical Engineering, Faculty of Medicine, Tehran University of Medical Sciences, \\ Tehran, Iran. \\ ${ }^{6}$ Radiology Department, Kabul University of Medical Sciences, Kabul, Afghanistan \\ ${ }^{7}$ Department of Health Services Management, Faculty of Management and Medical Information, Isfahan University of \\ Medical Sciences, Isfahan, Iran \\ ${ }^{8}$ Islamabad Gharb Health Network, Kermanshah University of Medical Sciences, Kermanshah, Iran \\ ${ }^{9}$ Department of Public Health Management, Faculty of Public Health, Kabul University of Medical Sciences, Kabul, \\ Afghanistan \\ ${ }^{10}$ Medical Research Center, Kateb University, Kabul, Afghanistan \\ ${ }^{11}$ Tetabyte Education Organization, Qom, Iran
}

\begin{abstract}
Objectives: The success or failure of global and national efforts to combat the COVID-19 pandemic depends on public knowledge, attitude, and practice. Iran, Afghanistan, and Turkey are among the most affected countries in which they have approximately similar socio-cultural structures. This is an online questionnaire-based cross-sectional study to assess the knowledge, attitude, and practice levels toward the COVID-19 pandemic among the adult population of these nationalities.
\end{abstract}

Methods: A total of 2736 individuals including 1080 from Turkey, 1025 from Iran, and 631 from Afghanistan responded to the questionnaire. The data was collected online through a survey using the Google form and Porsall platforms. In addition to demographic characteristics, the questionnaire consists of three main sections including items of awareness, attitude, and practice of the participants about COVID-19 using four Likert scale questions. Descriptive statistics were used to estimates the proportions of items. One-way analysis of variance (ANOVA) and independent T-test was used to analyze the difference between KAP scores among sociodemographic variables and between countries. All analyses were done with the $95 \%$ confidence level and the significant level was defined as $p$ value $<0.05$

Results: Overall KAP scores were over 3 out of 4 among Turkey, Iran, and Afghanistan respectively. Despite no differences between subpopulations in each country, the overall attitude and practice score of the Afghan population was significantly lower than Turkish and Iranian populations (P-value <0.05).

Conclusion: In spite of the high level of knowledge, positive attitude, and acceptable practice in all populations understudy, a low-risk perception in a considerable part of the population was discerned. J Microbiol Infect Dis 2021; 11(2):58-65.

Keywords: Knowledge, attitude, practice, COVID-19

Correspondence: Abbas Ali Husseini, Istanbul Gelisim University, Life Science and Biomedical Engineering Application and Research Center, Istanbul 34310, Turkey

Email: ahusseini@gelisim.edu.tr

Received: 03 December 2020 Accepted: 31 May 2021

Copyright (C JMID / Journal of Microbiology and Infectious Diseases 2021, All rights reserved 


\section{INTRODUCTION}

In late 2019, a novel coronavirus infection later named the COVID-19 epidemic suddenly hit Wuhan, China, and subsequently spreading all around the world and convert to a severe global pandemic ever since [1]. High transmissibility among the population and fatalities rate in specific high-risk groups made this novel infection a high-impact health threat [2]. Now, the disease has established in almost all countries and until the middle of September 2020, approximately 31 million cases with over 957 thousand death officially was reported all around the world [3].

The governments developed country-specific preventive measures, in line with WHO guidelines. These may include suspending all incoming and outgoing flights, closing all shopping malls, schools, and universities in the country, quarantine, and lockdown practices. However, after the first wave of the pandemic, some countries have experienced a second or even third wave of the pandemic.

Despite unprecedented national and global measures to combat the outbreak continues, the success or failure of these efforts largely depends on public knowledge, attitude, and practice. Evidence shows that public awareness and attitude are important in combating the pandemic $[4,5]$. By evaluating the public's awareness of the coronavirus, deeper insights into current public perception and practices can be achieved, thereby helping to identify characteristics that affect the population in adopting healthy practices, and sensitive behaviors [6]. Evaluating public knowledge, attitude, and behavior is also important in identifying gaps and strengthening ongoing prevention efforts. Iran, Afghanistan, and Turkey are among the most affected countries in which they have approximately similar socio-cultural structures. Attitude evaluation studies conducted in Turkey mostly have done among health workers [7-12], and little attention has been made on the public. The previous studies among Iranian belong to the early stage of pandemic and also are controversial [13-15]. No study previously was done in Afghanistan in this regard. In the current study, the knowledge, attitude, and practice of the adult population of Iran, Afghanistan, and Turkey toward COVID-19 preventive measurements are investigated.

\section{METHODS}

This cross-sectional study was conducted among Turkey, Iran, and Afghanistan adult population to assess the public's knowledge, attitudes, and practices regarding the Coronavirus outbreak. This study aimed to maximize access and collect data from as many participants as possible.

However, the sample size was calculated as 666 participants for each country based on $\pm 5 \%$ margin of error, $99 \%$ confidence level, $50 \%$ response distribution, and country population. The data was collected online through a survey using the Google form and Porsall platforms.

On the first page of the online survey, participants were informed about the background and objectives of the study. The survey consisted of four main sections. In the first part, information regarding the sociodemographic characteristics of the participants such as age, gender, education level, occupational, residential area, and income level was collected. The second part evaluated the participants' knowledge about COVID-19. This section included 4 items on the ways of transmission, clinical symptoms, prevention, and control. The third and fourth sections evaluated the attitude and practice of participants using four Likert scale questions. Questionnaires with similar content were prepared based on local official languages for each country.

\section{Statistical analysis}

Once data were collected, all questionnaires were then entered into a customized Excelbased system. Descriptive statistics were then generated for national-level estimates (proportions). One-way analysis of variance (ANOVA) was used to analyze the difference between KAP scores among sociodemographic variables in each country. An independent T-test also was used for comparing the scores between countries. All analyses were done with the $95 \%$ confidence level and the significant level was defined as $p$-value $<0.05$.

\section{RESULTS}

A total of 2736 individuals including 1080 from Turkey, 1025 from Iran, and 631 from Afghanistan responded to the questionnaire. The male to female ratio in different countries was $366 / 655, \quad 401 / 614$, and 502/129 
respectively. Most of the respondents (63.3\%) were $20-39$ years old range and $79.3 \%$ of all respondents had an academic education. The socio-demographic characteristics of participants are summarized in Table 1.

\section{Knowledge of Coronavirus transmission,} signs, prevention, and control

Overall knowledge scores were 3.4, 3.2, and 3.2 out of 4 among Turkey, Iran, and Afghanistan respectively. There were no significant differences between genders, age groups, education levels, and occupational categories intra-countries. Besides, no significant differences in knowledge scores also were found among countries. However, the awareness rate of transmission, signs, prevention and control were varied among different populations.

Among all Turkish respondents, 94.7\% were aware that the virus may spread through cough and sneeze. In contrast, $89.5 \%$ of Iranian and $85.5 \%$ of Afghan respondents were aware of this regard. Respectively, $91.5 \%, 87.8 \%$, and $74 \%$ of the Turkish population were aware that near distance, handshaking, and hugging, and touching objects may cause transmission of the virus. However, these ratios were $68.4 \%, 77.2 \%$, and $65.5 \%$ among Iranian respectively while were $65.4 \%, 80.9 \%$, and $66.7 \%$ among the Afghan population.

Table 1. Socio-demographic characteristics of participant's summaries.

\begin{tabular}{|c|c|c|c|c|}
\hline Variables & & Iran \% & Afghanistan \% & Turkey \% \\
\hline \multirow[t]{2}{*}{ Gender } & Male & 39,1 & 79,5 & 35,9 \\
\hline & Female & 59,9 & 20,5 & 64,1 \\
\hline \multirow[t]{7}{*}{ Age } & <20 yrs. & 9,7 & 1,6 & 2,9 \\
\hline & $20-29$ & 37 & 52,9 & 30,7 \\
\hline & $30-39$ & 64 & 31,7 & 24,1 \\
\hline & $40-49$ & 28 & 8,9 & 21 \\
\hline & $50-59$ & 14 & 3,2 & 13,6 \\
\hline & $60-69$ & 3,5 & 1,6 & 6,7 \\
\hline & $>70$ yrs. & 0,8 & 0,1 & 1 \\
\hline \multirow[t]{4}{*}{ Education } & Primary & 2 & 0 & 2,6 \\
\hline & Secondary & 3,6 & 1,3 & 3,7 \\
\hline & High school & 17,8 & 2,7 & 15,7 \\
\hline & University & 77,3 & 96 & 77,9 \\
\hline \multirow[t]{10}{*}{ Occupation } & Academics and teachers & 16,5 & 19,8 & 11,7 \\
\hline & Health workers & 19,8 & 13,5 & 19,4 \\
\hline & Engineers and technical affairs & 4,3 & 4,4 & 9 \\
\hline & administrative and financial affairs & 36,8 & 21,4 & 15 \\
\hline & self-employee & 5,9 & 1,3 & 3,2 \\
\hline & housewife & 26,3 & 0,5 & 7,8 \\
\hline & Student & 17 & 11,4 & 7,4 \\
\hline & Retired & 4,7 & 0,1 & 5,7 \\
\hline & Jobless & 5,5 & 5,4 & 1,8 \\
\hline & Other & 2,5 & 0,95 & 4,3 \\
\hline
\end{tabular}

Overall, $97.8 \%, 92.4 \%$, and $90.2 \%$ of the and dyspnea as key symptoms of infection Turkish respondents identified fever, dry cough, respectively. Among Iranian respondents, 
$79.2 \%, \quad 77.4 \%$, and $76.6 \%$ of individuals expressed fever, dry cough, and loss of taste or smell as the most common symptoms. However, the awareness of fatigue and dyspnea, the two other common symptoms were $71.3 \%$ and $70.3 \%$ respectively. In this regard, $87 \%, 83.2 \%$, and $81.4 \%$ of Afghan respondents respectively mentioned fever, muscle or body aches, and loss of taste or smell as common symptoms. Also, $78.9 \%$, and $75.1 \%$ respectively aware of fatigue and dry cough as the common signs of infection.

Besides, $82.8 \%$ and $73.1 \%$ of Turkish, $69.6 \%$, and $73 \%$ of Iranian, and $67.5 \%$, and $78.4 \%$ of Afghan respondents were aware of the necessary time for quarantine, and minimum time of effective hands washing.

\section{Attitudes towards pandemic preventive measurements.}

The overall attitude scores were 3.4, 3.4, and 3.1 out of 4 among Turkish, Iranian, and Afghan respondents respectively. In spite of no differences between subpopulations in each country, the overall attitude score of the Afghan population was significantly lower than Turkish and Iranian populations (P-value: 0.03).

Approximately $78 \%$ of the Turkish, $77.8 \%$ of Iranian, and $63.4 \%$ of Afghans have expressed that have concerns about the re-increasing of Covid-19 where others have either had little or no concern in this regard. In the same way, respectively $89 \%, 65 \%$, and $78.9 \%$ of the respondent on each country think that know how they can protect themselves and their families. Also, $94.4 \%$ of Turkish respondents were shown interest in quarantine measurement. In contrast, respectively about $20 \%$ and $22.6 \%$ of Iranian and afghan respondents were shown little or no interest.

However, about $13.8 \%$ to $20.5 \%$ of people did not felt to need their environments and equipment to be disinfected. The majority of participants agreed on the possibility of transmission from individuals without symptoms. Despite, the probability rate varied, $5.9 \%$ of Turkish was thinking that possibility is low while $21.4 \%$ of Iranian and $31.8 \%$ of Afghan respondents believed that transmission from individuals without symptoms is impossible or their possibility is very low. On the other hand,
$25.7 \%, 28.7 \%$, and $32.5 \%$ of the study population felt that the risk of the pandemic was somewhat exaggerated.

The attitude on preventive actions such as hands washing, mask-wearing, quarantine, and traveling lockdown was varied among nationalities. In contrast to Turkey and Iran which approximately $95.7 \%$ of people thought that hands washing and quarantine actions can effectively prevent the infection, respectively $10.9 \%$ and $7.5 \%$ of Afghan respondents were not believed in. On the other hand, $96 \%$ of Iranian and $90 \%$ of Turkish respondents look positive about wearing the mask as an effective measurement where $15.5 \%$ of Afghan respondents were shown a weak attitude. Similarly, $12.8 \%$ of Turkish, $6.2 \%$ of Iranians, and $14.5 \%$ of Afghans respondents did not agree with traveling lockdown as an effective measurement.

Among Turkish respondents, $75.8 \%$ strictly said that they would go to a testing center for tests if they would have COVID-19 symptoms while $1.5 \%$ strictly rejected it. These ratios for Iranian respondents were $58.9 \%$ and $6.1 \%$ and for Afghan respondents were $26.6 \%$ and $36.5 \%$ respectively. The others were hesitant.

The majority of the population in all study populations felt a degree of responsibility for not transmitting the disease to others. Only $1 \%$ of Turkish and Iranian respondents and $1.7 \%$ of Afghan respondents mentioned that they do not feel responsible in this regard.

\section{Individual protective practice}

The practice scores among Turkish people, Iranians, and Afghans respectively were 3.4 , 3.5, and 3.1. Despite there were no significant differences between Turkey and Iran scores, the overall practice score of Afghans was significantly lower than the two other nations. (Pvalue: 0.004 and 0.04). Besides, no differences were found between sociodemographic groups in each country.

In contrast to Afghan respondents that only $28 \%$ effectively avoid crowded places, $45.7 \%$ of Turkish and $52 \%$ of Iranians never or seldom were found at the high-risk places. Healthy practices such as hands washing, wearing masks, disinfection environment, handshaking, and hugging habits, and care about social 
distance extremely changed in a positive way during the pandemic. In terms of handwashing $79.5 \%$ of Turkish people, $90 \%$ of Iranians, and $80 \%$ of Afghans used to care more than in the past. In the same way, $63.2 \%, 82.7 \%$, and $58.8 \%$ of respondents respectively in each country regularly provide alcohol and disinfectants during the pandemic. In addition, $95 \%$ of Turkish people, $89.6 \%$ of Iranians, and $46.5 \%$ of Afghan respondents wear a mask out of home regularly. Likewise, respectively $80.1 \%$, $84.4 \%$, and $60.3 \%$ avoid handshaking and hugging in friendship meetings. Although the majority of the population takes care of social distance, respectively $9.9 \%, 16.7 \%$, and $19.5 \%$ of people in each country have less or no attention to social distance. Also, respectively $1.1 \%, 0.8 \%, 2.3 \%$ of respondents express that they do not use to cover mouth and nose while sneezing or coughing.

\section{DISCUSSION}

This study was conducted to evaluate the knowledge, attitude, and practice of the adult population of Turkey, Iran, and Afghanistan concerning the COVID-19 pandemic and preventative measurements. Public evaluation in this regard showed that KAP scores were at least over 3 out of 4 which means a relatively high knowledge, positive attitude on preventative measurements, and healthy practice among participants. The results of this study show approximately similar KAP scores among different sociodemographic groups in intracountries. Albeit these results show a higher knowledge score in Turkish people but there were no significant differences amongst countries. In contrast, the attitude and practice scores of Afghan respondents were significantly lower than two other countries.

The present study indicates a homogeneity at the knowledge level of three countries' people. The result also shows that knowledge of the public in terms of transmission ways, infection symptoms, and preventative actions at least is as high as health professionals. It may be as a result of presenting massive information in all countries to all subpopulations. In Turkey, previous studies among health workers are in line with our results. For example, Kara E et al who investigated the knowledge and attitudes among hospital pharmacists about COVID-19 reported that $91 \%$ of participants were enough familiar with transmission ways, as well as the main symptoms such as fever $(92.4 \%)$, cough (84.4\%), and dyspnea (60.3\%). Moreover, washing hands with soap (92.0\%), using hand disinfectants $(80.6 \%)$, and avoiding contact with sick people $(81.9 \%)$ were popular answers for protection from the disease [8]. The result of the study also is consistent with the study which showed knowledge of medical students was high [11]. In Iran, some of the former studies showed a high knowledge among both health professionals and the public, while later, other studies reported lower knowledge and practice among elders, men, and lower education levels $[13,14,15]$. In Afghanistan, there have been studies that represent high knowledge, attitude, and practice regarding COVID-19 among medical students and health workers [16, 17]. Studies carried out among the public also show high knowledge levels among the population [18]. In line with attitude and practice toward COVID-19 preventive measures among the public, this study is the first, which has done in Afghanistan. Its findings indicate a positive attitude and practice toward preventive measurements among adults. In contrast to Turkey and Iran, the level of attitude and practice in Afghanistan is significantly low. Despite rapid response teams actively engage in diagnosis, treatment, and prevention, health education programs are not sufficient in Afghanistan. Therefore, Afghanis are reluctant to involve social activities due to insufficient information support programs, dissatisfactory health services, low level of trust in the ruling system, and poverty leading to lower attitude and practice level among the population [19].

The KAP study emphasized $37 \%$ of Afghan respondents perceived COVID 19 as a low-risk phenomenon. This finding is consistently supported by the following study that shows $45.8 \%$ of Afghans believed it was "very unlikely" for them to be infected with COVID-19 [20]. Likewise, Iranian risk perception was low which is consistent with the study that $32.3 \%$ Iranian population perceived themselves as not susceptible to COVID-19 [21]. In Turkey, the low-risk perception was determined in $24 \%$ of the individuals [22]. Risk perception itself can influence health-related behaviors toward avoiding risky behaviors [23]. Accurate risk 
perception in the conscious, emotional, and experiential levels interactively can influence health behaviors [23]. Approximately $10 \%$ of people do not care about social distancing and visiting crowded places which potentially increases the chance of rotating and spreading the virus.

An Individual's health-related practice is made and can be changed into a continuous process of the knowledge-attitude-practice model [24]. Attitudes of people as a mediator between their knowledge and practices have an important role in the better controlling pandemic of infectious diseases; they facilitate the process of changing people's behavior. Attitude is a term of social psychology with three components such as affective or feeling, cognitive or knowledge, and behavioral components [25]. In other words, a set of emotions, beliefs, and behaviors toward a certain thing or event has been considered as an attitude that implicitly influences other variables like knowledge and practice. Likewise, attitude itself covers knowledge which is a cognitive part of humans, and practice as a behavioral part. People's responses to COVID 19 and its aspects could be controlled by their attitudes toward social efforts to defeat and prevent the harmful effects of COVID 19. If they hold negative effects on the government and its efforts against COVID 19, they will be expected not to behave or practice effectively preventive measurement and vice versa. Moreover, if they believe that is dangerous enough and perceive it as risky, they will behave according to the health protection program.

Given the lower score in attitude and practice in Iran and Afghanistan, it is thought that communication with people to change their behavior and attitude has not been strong enough to be persuasive. Persuasion is described as "human communication that is designed to influence others by modifying their beliefs, values, or attitudes" [26].

There are four theories to explain how a message can be persuasive enough to boost a certain attitude and behavior including Social Judgement theory (SJT), Elaboration likelihood model (ELM), Cognitive dissonance theory (CDT), and narrative paradigm [20].

According to Social Judgement theory (SJT), the preexisting attitudes determine if a message will be rejected and it will be True persuasion if the persuasive message falls at the edges of people's latitude of acceptance [27]. Therefore, the messages about COVID 19 in Iran and Afghanistan might not have fallen within the latitude of receivers' acceptance or might be in contrast to preexisting attitudes toward senders. In this regard, approximately $22 \%$ of Turkish and Iranian as well as $37 \%$ of Afghan respondents perceived COVID 19 as a low-risk phenomenon. Also, minimally one of the fourth of the population in all countries under study $(25.7 \%$ $32 \%)$ thinks that the dangers of the pandemic have been exaggerated. In order to improve people's judgment for perceiving COVID 19 as high-risk health issues, building social groups can be a byproduct of this theory will raise the community individual's attitude. Such spontaneous social groups in preventive activities play an important role in succeeding the taken measurements as well as increasing the attitude of society.

The second theory of persuasion is the Elaboration likelihood model (ELM) also emphasizes receivers' motivation and ability to process elaborated messages. Given low cooperative subjects in all three countries, they are supposed to be unmotivated or unable to process information, peripheral cues should be used [27]. For example, they would agree to health preventive messages if the source appears to be accepted like experts, attractive like children, well-known like celebrities, unanimous like friends, and so on.

The third theory of persuasion that is applicable in this study is Cognitive dissonance theory (CDT) explains inconsistencies in beliefs and actions. The disparity between incongruent beliefs and behaviors would be solved through persuasion [27]. Living in a society that facing COVID 19 is inevitable but unwanted. We live and behave in settings that jeopardize our health as if it causes inconsistency between beliefs and behaviors. An extremely low score in selfreporting action attitude in Afghanistan might be a sign of cognitive dissonance. Boosting altruistic behavior will fill the gap and disparity between belief and behavior as an attitudechanging plan. For this purpose, launching and attracting charitable donations helps those who are actively involved in this endeavor achieve a positive attitude toward the injured society. 
The fourth theory of persuasion, the narrative paradigm is an emotional process based on storytelling and judging on the perceived truthfulness and consistency [20]. According to this theory, telling the story of COVID 19 should evoke empathy in people and increase sensitivity to the degree of risk for them.

There are some limitations to this research. First, the questions did not involve all aspects. Second, the convenience sample of each country was included in the study. Besides, people were able to self-select based on their interest and experience with the topic. It is possible that sample demographics may not completely represent the public adults and the generalizability of the result is weak because it has no random logic and infrastructure. The majority of respondents were universityeducated individuals which mainly familiar with smart technologies and social media which made them more approachable.

In terms of Afghanistan, the majority of respondents have a university degree. Therefore, the results from Afghanistan cannot reflect the public adults' knowledge, attitude, and practice situations. Participation of women in surveys is generally low in Afghanistan when the public is the target group [18]. It might due to the average women are not broadly using social media. It caused either difficult access to them or a low number of females participating in this research.

\section{Conclusion}

In spite of the high level of knowledge, positive attitude, and acceptable practice in all populations understudy, a low-risk perception in a considerable part of the population was discerned. Further study to evaluate the causal factors is suggesting. This can lead to filling the gaps in action plans.

\section{ACKNOWLEDGMENTS}

Declaration of Conflicting Interests: The authors declare that they have no conflict of interest.

\section{Funding: Not applicable REFERENCES}

1-Husseini AA, Kamil AA. Estimating COVID-19 Dynamics in Afghanistan. Erciyes Med J 2020; 42(4): 468 - 473. DOI: $10.14744 /$ etd.2020.80270
2- Husseini AA, Kamil AA, Aloudal MR. COVID-19 Disease and Interferon-y: Has it a Protective Impact on Mortality? Erciyes Med J 2020; 43(2): 116-121. DOI: 10.14744/etd.2020.40326

3- The Center for Systems Science and Engineering (CSSE) at JHU, JHU CSSE COVID-19 Dashboard. Available at 14.09.2020

4- Chirwa GC. Who knows more, and why? Explaining socioeconomic-related inequality in knowledge about HIV in Malawi. Sci African 2020; 7:e00213 DOI: 10.1016/j.sciaf.2019.e00213

5- Chirwa GC, Sithole L, and Jamu E, Socioeconomic Inequality in Comprehensive Knowledge about HIV in Malawi. Malawi Med J 2019; 31(2): 104111. DOI: $10.4314 / \mathrm{mmj} . \mathrm{v} 31 \mathrm{i} 2.1$

6- Podder D, Paul B, Dasgupta A, Bandyopadhyay L, Pal A, Roy S. Community perception and risk reduction practices toward malaria and dengue: a mixed-method study in slums of Chetla, Kolkata. Ind J Public Health 2019; 63:178. DOI: 10.4103/ijph.IJPH_321_19

7- Erbas M, Dost B. (2020) Evaluation of knowledge and attitudes among intensive care physicians during the COVID-19 pandemic: a cross-sectional survey. Sao Paulo Med J. 2020; S1516-31802020005014103. DOI:10.1590/1516-3180.2020.02545062020

8- Kara E, Demirkan K, Ünal S. Knowledge and Attitudes Among Hospital Pharmacists About COVID19. Turk J Pharm Sci 2020; 17(3):242-248.

9- Duruk G, Gümüşboğa ZŞ, Çolak C. Investigation of Turkish dentists' clinical attitudes and behaviors towards the COVID-19 pandemic: a survey study. Braz Oral Res 2020; 34: e054. DOI:10.1590/18073107bor-2020.vol34.0054

10- Dost B, Koksal E, Terzi Ö, Bilgin S, Ustun YB, Arslan HN. Attitudes of Anesthesiology Specialists and Residents toward Patients Infected with the Novel Coronavirus (COVID-19): A National Survey Study. Surg Infect (Larchmt) 2020; 21(4):350-356. DOI:10.1089/sur.2020.097

11- Yakar B , Kaygusuz TÖ , Pirinçci E , Önalan E, Ertekin $\mathrm{YH}$, Knowledge, attitude and anxiety of medical students about the current COVID-19 outbreak in Turkey. Fam Pract Palliat Care 2020; 5(2):36-44 DOI: 10.22391/fppc.737469

12- Çolakoğlu MK, Özgün YM, Pişkin E, Bostancı EB, Özmen MM. The attitude of Turkish general surgeons during the COVID-19 pandemic: Results of "general surgery COVID-19 pandemic attitude survey". Turk J $\begin{array}{lllll}\text { Surg 2020; } 36 & \text { (2): } 137-146 \text { DOI: }\end{array}$ 10.5578/turkjsurg.4809

13-Taghrir MH, Borazjani R, Shiraly R. COVID-19 and Iranian Medical Students; A Survey on Their RelatedKnowledge, Preventive Behaviors and Risk Perception. Arch Iran Med 2020; 23(4):249-254. DOI:10.34172/aim.2020.06 
14- Honarvar B, Lankarani KB, Kharmandar A, et al. Knowledge, attitudes, risk perceptions, and practices of adults toward COVID-19: a population and fieldbased study from Iran. Int J Public Health 2020; 65(6):731-739. DOI: 10.1007/s00038-020-01406-2

15- Kakemam E, Ghoddoosi Nejad J, et al. Knowledge, attitudes, and practices among the general population during COVID-19 outbreak in Iran: A national cross-sectional survey. 2020, Medrxiv, preprints DOI:10.1101/2020.06.10.20127258

16- Nemat A, Raufi N, Sediqi MF, Rasib AR, Asady A. Knowledge, Attitudes, and Practices of Medical Students Regarding COVID-19 in Afghanistan: A Cross-Sectional Study. Risk Manag Healthc Policy. 2021; 14:1491-1497.

17- Bhagavathula AS, Raghavan VR, Ahmadi A, Srirag D, Chattu VK, Frontline Healthcare Workers' Knowledge, Perception and Risk Prevention Practices Regarding COVID-19 in Afghanistan: A CrossSectional Study. Med. Sci. 2021, 9, 2. https://doi.org/10.3390/ medsci9010002

18- Orfan SN and Elmyar $\mathrm{AH}$. Public knowledge, practice and attitudes towards COVID-19 in Afghanistan. Public Health of Indonesia: 6(4), 104-115

19- IOM UN migration, COVID-19 Rapid Response, Mobile Clinics in Afghanistan Receive New Funding Support URL: https://www.iom.int/news/covid-19rapid-response-mobile-clinics-afghanistan-receivenew-funding-support access 08.06.2021

20- Mousavi SH, Delshad MH, Acuti Martellucci C, et al. Community behavioral and perceived responses in the COVID-19 outbreak in Afghanistan: A crosssectional study. Disaster Med Public Health Prep. doi: https://doi.org/10.1017/ dmp.2021.135.

21- Jahangiry L, Bakhtari F, Sohrabi Z, Reihani P, Samei S, Ponnet K and Montazeri A. Risk perception related to COVID-19 among the Iranian general population: an application of the extended parallel process model. BMC Public Health (2020) 20:1571 https://doi.org/10.1186/s12889-020-09681-7

22- Cihan E, Pirinççi CŞ, Gerçek H, Ünüvar BS, Demirdel E. The Knowledge Levels, Preventive Behavior and Risk Perception On COVID-19 of the Healthcare Students In Turkey. SDÜ Sağlık Bilimleri Dergisi 2020; 11(3):342-347. Doi:

$10.22312 /$ sdusbed.765212

23- Ferrer $\mathrm{R}$ and Klein WM, Risk perceptions and health behavior, Curr Opin Psychol 2015; 5: 85-89. DOI:10.1016/j.copsyc.2015.03.012

24- Liu L, Liu YP, Wang J, An LW, Jiao JM. Use of a knowledge-attitude-behaviour education programme for Chinese adults undergoing maintenance haemodialysis: Randomized controlled trial. J Int Med Res 2016; 44(3): 557-568. DOI: $10.1177 / 0300060515604980$

25- Heinzen T and Goodfriend W, Social psychology, 1st Edition ed., SAGE Publications, Inc; 2017: 632
26- Simons HW, Persuasion: understanding, practice, and analysis, Reading, MA: Addison-Wesley Publishing Co. 1976: 382

27- Dainton M, "Explaining Theories of Persuasion," in Applying Communication Theory for Professional Life: A Practical Introduction, Second Edition ed., SAGE Publications, Inc, 2010: 103-131. 